\title{
Louis Van Delft, Les spectateurs de la vie. Généalogie du regard moraliste
}

\section{Benedetta Papasogli}

\section{Q OpenEdition}

1 Journals

\section{Edizione digitale}

URL: https://journals.openedition.org/studifrancesi/26178

DOI: 10.4000/studifrancesi.26178

ISSN: 2421-5856

\section{Editore}

Rosenberg \& Sellier

\section{Edizione cartacea}

Data di pubblicazione: 1 avril 2007

Paginazione: 169-170

ISSN: 0039-2944

\section{Notizia bibliografica digitale}

Benedetta Papasogli, «Louis Van Delft, Les spectateurs de la vie. Généalogie du regard moraliste», Studi Francesi [Online], 151 (LI | I) | 2007, online dal 30 novembre 2015, consultato il 23 novembre 2021. URL: http://journals.openedition.org/studifrancesi/26178; DOI: https://doi.org/10.4000/studifrancesi. 26178

Questo documento è stato generato automaticamente il 23 novembre 2021.

\section{(c) 9 (i) $\Theta$}

Studi Francesi è distribuita con Licenza Creative Commons Attribuzione - Non commerciale - Non opere derivate 4.0 Internazionale. 


\title{
Louis Van Delft, Les spectateurs de la vie. Généalogie du regard moraliste
}

\author{
Benedetta Papasogli
}

\section{NOTIZIA}

LOUIS VAN DELFT, Les spectateurs de la vie. Généalogie du regard moraliste, Les Presses de

l'Université Laval, 2005, pp. 314.

Dopo un libro tutto italiano, Frammento e anatomia, pubblicato nel 2004 presso il Mulino, Louis van Delft offre una nuova raccolta di saggi sulla moralistica classica, nella quale vari spunti critici che hanno dimostrato negli anni la loro fecondità si compongono in un intreccio suggestivo. Per chi ha seguito il percorso critico di questo studioso che ha insegnato a tutta una generazione come leggere i moralisti e direi, più sostanzialmente: perché leggerli, ampliando continuamente il campo d'indagine, convocando sempre più spesso approcci interdisciplinari, non sarà difficile riconoscere in questo libro (e nell'ultimo sopra menzionato) una tappa nuova nel solco degli studi precedenti. Il titolo, derivato da Montaigne, ma che sembra anche coniugare la reminiscenza di The Spectator di Addison e Steele con la definizione di Dilthey "i filosofi della vita", ci riconduce a un tema messo da Van Delft già al cuore del suo Moraliste classique: il teatro del mondo, rispetto al quale il moralista ricava un suo spazio di osservazione e di critica, sia il retrobottega di Montaigne o il "cabinet" aperto, accogliente, del filosofo secondo La Bruyère. Ma il sottotitolo, facendo emergere il motivo dello sguardo, richiama una più recente angolatura critica, che studia la visione dei moralisti in rapporto con l'ottica del loro tempo (cfr. il bel volume a cura di Bernard Roukhomovsky, L'optique des moralistes, 2005). Il teatro di cui si parla nel libro è, d'altronde, sempre più un teatro interiore, quel teatro della memoria nel cui cerchio aperto le cose della vita sono rappresentate e significate. Ed è anche l'anfiteatro anatomico nel quale il corpo umano, luogo e metafora dell'anima, viene esplorato profondamente, attraverso quella tecnica di incisione e separazione che offre una analogia al lavoro analitico del moralista. In tal modo, sul filo di idee e di metafore, l'approccio critico di Van Delft 
trapassa dall'ambito dei temi del discorso morale a quello dello stile e delle forme: nell'ultima parte del libro emerge la questione del frammento, che Van Delft, a differenza di altri critici specie francesi, non distingue nella sua sostanza dalla forme breve dei classici (contribuendo così a sottolineare, al di là di alcune storiche fratture, la continuità plurisecolare e il respiro europeo della scrittura aforistica).

2 Non vogliamo render conto dei singoli saggi confluiti in questo volume, che ha al centro tre medaglioni: Montaigne, La Rochefoucauld, La Bruyère. Mi pare importi soprattutto mettere in luce il procedere di un metodo critico attraverso l'“invenzione" di strumenti e di modelli, di cui alcune parole divengono come l'icona: teatro e ottica, economia e anatomia, memoria e frammento. Il capitolo su La Rochefoucauld ha il valore di un manifesto: lancia l'idea di un "modello anatomico" dell'analisi morale, avvicinata in tal modo all'ambito delle scienze, ma anche a quello della spiritualità contemporanea, che si avvaleva delle stesse immagini. I diversi saggi sulla memoria sviluppano una sequenza di grande coerenza, andando a occupare uno specifico, originale settore nella fioritura di studi sulla memoria dei classici. Vi è d'altronde una circolarità di motivi, per cui ognuna delle angolature richiama le altre, e il discorso critico procede su una sottile combinatoria, così come la scrittura discontinua dei moralisti costruiva, senza parere, le proprie reti. Dai suoi autori prediletti Van Delft ha appreso il valore del cerchio aperto e della ripetizione suasiva, che non impedisce il progresso o lo slancio innovatore dell'immaginario critico, in questi ultimi libri particolarmente attestato. 